\title{
Behavioral thermoregulation at high environmental temperatures: Effect of variation in intensity of heat stimulus and magnitude of reinforcement
}

\begin{abstract}
DONALD A. KRISTT, New York University Medical Center, New York, N.Y. 10016 and Department of Social Sciences, Polytechnic Institute of Brooklyn, New York, N.Y. 11201, and JERI A. SECHZER, Departments of Rehabilitation Medicine and Anatomy, New York University Medical Center, New York, N. Y. 10016

Subjects that have learned to bar-press for a blast of cold air in a "hot" environment, discriminate the difference between a 14-deg C blast of air and a 24-deg C blast of air. This discrimination is evidenced by a decrease in rate of obtaining reinforcement when the temperature of the reinforcement is $14 \mathrm{deg} C$. The Ss were able to make this discrimination at an environmental temperature of $37 \mathrm{deg}$ and $45 \mathrm{deg} C$, but not at $55 \mathrm{deg} C$. The rate of reinforcement at a particular reinforcement temperature increases as the temperature of the environment is elevated.
\end{abstract}

Recent work by several investigators (Weiss \& Laties, 1960; Carlisle, 1966) has shown that rats, bar-pressing for heat reinforcement in a cold environment, decreased their rate of obtaining reinforcement as the intensity of the reinforcement increased. Moreover, it has been found that the reinforcement rate is also inversely proportional to the environmental temperature. In contrast, Epstein (1968) trained Ss to work for a spray of water at high ambient temperatures and demonstrated that the rate of reinforcement varied directly with the environmental temperature. The present experiment was carried out to study changes in reinforcement rate (a) at different environmental temperatures, and (b) when due to differences in the magnitude, i.e., temperature, of the reinforcement. The $S s$ in this experiment, when placed in a "hot" environment, bar-press for a blast of cold air.

\section{SUBJECTS}

The Ss were four naive male SpragueDawley rats. They were weight stabilized for the 2 weeks prior to the experiment and during its course at $325 \pm 5 \mathrm{~g}$. Water was available on a schedule of $50 \mathrm{ml}$ every $12 \mathrm{~h}$. All Ss were individually housed in metal cages. The ambient temperature was $23 \pm 2$ deg C. During the experiment each $S$ was run at approximately the same time of day to allow for possible effects of the diumal adrenal cycle.
Table 1

Summary of conditions under which experiment was performed. $T_{E}$ is environmental temperature (deg C); $T_{R F}$ is temperature of reinforcement (deg $C$ ). Each condition represents a separate 3 -h session.

\begin{tabular}{|c|c|c|c|c|c|c|}
\hline Condition & $\mathbf{T}_{\mathbf{E}}$ & $\mathbf{T}_{\mathbf{R F}}$ & $\mathbf{T}_{\mathbf{E}}$ & $\mathbf{T}_{\mathrm{RF}}$ & $\mathbf{T}_{\boldsymbol{E}}$ & $\mathbf{T}_{\mathbf{R F}}$ \\
\hline $\begin{array}{l}1 \\
2 \\
3 \\
4 \\
5\end{array}$ & $\begin{array}{l}37 \mathrm{deg} \\
45 \mathrm{deg} \\
55 \mathrm{deg} \\
37 \mathrm{deg} \\
37 \mathrm{deg}\end{array}$ & $\begin{array}{l}24 \mathrm{deg} \\
24 \mathrm{deg} \\
24 \mathrm{deg} \\
14 \mathrm{deg} \\
24 \mathrm{deg}\end{array}$ & $\begin{array}{l}37 \text { deg } \\
45 \mathrm{deg} \\
55 \mathrm{deg} \\
37 \mathrm{deg} \\
37 \mathrm{deg}\end{array}$ & $\begin{array}{l}14 \mathrm{deg} \\
14 \mathrm{deg} \\
14 \mathrm{deg} \\
24 \mathrm{deg} \\
24 \mathrm{deg}\end{array}$ & $\begin{array}{l}37 \mathrm{deg} \\
45 \mathrm{deg} \\
55 \mathrm{deg} \\
37 \mathrm{deg} \\
37 \mathrm{deg}\end{array}$ & $\begin{array}{l}24 \mathrm{deg} \\
24 \mathrm{deg} \\
24 \mathrm{deg} \\
14 \mathrm{deg} \\
24 \mathrm{deg}\end{array}$ \\
\hline
\end{tabular}

\section{METHOD}

The Ss were trained to depress a bar for a reinforcing 5 -sec burst of air. Bar presses during this 5 -sec period did not produce additional cooling. The temperature of the air was either $14 \pm 1 \mathrm{deg} C$ or $24 \pm 2 \mathrm{deg} C$. A small red pilot light was lit during the $5 \mathrm{sec}$ of each reinforcement. This discriminative stimulus helped to stabilize the S's performance (Carlton \& Marks, 1958) and decrease training time. The training and testing apparatus consisted of a modified Skinner box, $5 \times 9 \times 8$ in. high, placed within an environmental chamber at a temperature which was stable to $\pm 2 \mathrm{deg} \mathrm{C}$. $^{2}$ The Ss were taught the task in two stages. Stage 1 involved 6-12 15-min shaping sessions per $S$. Shaping was carried out till Ss reached a criterion defined as (1) head above bar and (2) paws on bar. In the session following attainment of criterion Ss were shaped for $15 \mathrm{~min}$ and were then left to self-train in a session lasting from $1.5 \mathrm{~h}$, depending on the latency to commencement of bar pressing.

In Stage 2, training was continued in $1-h$ sessions until stabilization in rate of obtaining reinforcement and "efficiency" was achieved. Efficiency is defined as the number of reinforcements per number of responses in a single session. Stabilization criterion was set at an efficiency level of $80 \%$ or better for four sessions prior to the actuál experiment and required from 13 to $19 \mathrm{~h}$. All training was carried out at an environmental temperature ( $\left.T_{E}\right)$ of $37 \mathrm{deg} \mathrm{C}$ and a reinforcement temperature of $24 \operatorname{deg} C$.

The actual experiment was composed of five, 3-h sessions per $S$. Each session was divided into three 1-h parts. The plan for the five sessions is found in Table 1. Ordering of the conditions was randomized for each S. Each condition represents one session. At the end of every hour the number of reinforcements and responses were recorded.

\section{RESULTS}

The results for a single $S$ are found in Table 2. In order to allow for possible interactions due to sequential changes in the temperature of the reinforcement, Table 2 only compared the number of reinforcements for the second and third hours. This was done for two reasons: (a) by this means one reinforcement condition always follows
Table 2

The complete data for a typical S, rat GB, at all five experimental conditions (Table 1). S.L. refers to the level at which the $S$ stabilized for the four sessions prior to the experiment. $T_{E}$ is environmental temperature; RF is the number of reinforcements and EFF is the efficiency of the performance and is defined as number of reinforcements per number of responses. R37 deg is Condition 4 in Table 1 ; Condition 5 results are given below the double horizontal ine.

\begin{tabular}{|c|c|c|c|c|c|}
\hline \multirow{2}{*}{\multicolumn{2}{|c|}{ Condition }} & \multicolumn{2}{|c|}{ Hour 2} & \multicolumn{2}{|c|}{ Hour 3} \\
\hline & & $\mathbf{R F}$ & $\operatorname{EFF}(\%)$ & RF & EFF(\%) \\
\hline 1 & $\begin{array}{l}\text { S.L. } \\
T_{E}=37 \mathrm{deg}\end{array}$ & -- & $-\overline{73}$ & $\begin{array}{l}74.7 \\
61\end{array}$ & $\begin{array}{l}81 \\
78\end{array}$ \\
\hline 2 & $T_{E}=45 \mathrm{deg}$ & 55 & 65 & 113 & 70 \\
\hline 3 & $T_{E}=55 \mathrm{deg}$ & 202 & 57 & 226 & 58 \\
\hline 4 & R37 deg & 12 & 80 & 81 & 85 \\
\hline \multicolumn{2}{|c|}{ Hour I } & \multicolumn{2}{|c|}{ Hour 2} & \multicolumn{2}{|c|}{ Hour 3} \\
\hline RF & EFF & $\mathbf{R F}$ & EFF & $\mathbf{R F}$ & EFF \\
\hline 5.110 & 79 & 114 & 76 & 103 & 70 \\
\hline
\end{tabular}




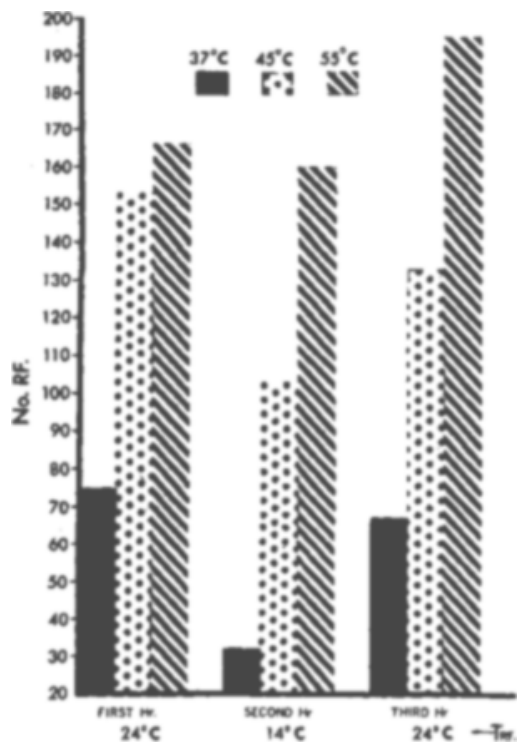

Fig. 1. Mean for all Ss of the number of reinforcements obtained at each hour of the experimental session for Conditions 1,2 and 3 (Table 1). The ordinate is the number of reinforcements (No. RF) and the abscissa indicates the sequential change in the temperature of the reinforcement $\left(T_{R F}\right)$.

the condition to which it is being compared, and (b) results for Hour 1 are comparable to those of Hour 3. Possible artifacts due to the length of the session (e.g., fatigue) were controlled for by running the $S s$ in Condition 5 (Table 1). From the data for Condition 5 (Table 2) it can be seen that the average rate of reinforcement seems fairly steady throughout the 3-h session. Although in some Ss the rate does decline somewhat from hour to hour, it never increases over that seen in the second hour. However, if we examine the columns "Hour 2" and "Hour 3" for Conditions 1, 2, and 4 (Table 2) we see a dramatic change between the second and third hours. This apparently reflects the S's ability to discriminate between the two cooling conditions and to consequently make an appropriate adjustment in behavior. For reasons we will consider below, this pattern doesn't appear when $T_{E}$ is $55 \operatorname{deg} C$. Whether the $S$ discriminates on the basis of his evaluation of a single reinforcement or a train of reinforcements remains an open question. This discrimination of the magnitude of the reinforcement is also observed in Fig. 1. Here, the mean rate of obtaining reinforcement for all Ss is compared for each hour of an experimental session at three different $T_{E}$ S. Figure 1 also shows that the $S s$ can discriminate varying intensities of the heat stimulus. For if we compare any particular hour at the three environmental temperatures we see a progressive increase in rate of reinforcement as the temperature is increased. This agrees well with Epstein's (1968) findings.

\section{DISCUSSION}

The data presented above suggests that a rat trained to bar-press for cool air can discriminate differences in the magnitude of reinforcement and intensity of the stimulus. The ability to make these discriminations enables the $S$ to adjust its activity and maintain a stable cooling level. This process of discriminating and adjusting in order to maintain thermal homeostasis is known as behavioral thermoregulation.

However, an alternate interpretation is possible, namely, that the only behavior that is thermoregulatory is the increase in rate of obtaining reinforcement as $T_{E}$ increases from $37 \mathrm{deg} \mathrm{C}$ to $55 \mathrm{deg} \mathrm{C}$. The depression in rate of reinforcement when the temperature of the reinforcement is $14 \mathrm{deg} \mathrm{C}$ may only be an avoidance response; naive $\mathrm{Ss}$ generally find the air burst aversive. Hence, the decrease in rate of reinforcement may merely be a response to the increased aversiveness of the "reinforcer."

Although we cannot entirely rule out this interpretation, the following considerations make it less convincing. First, an examination of Hour 2 in Fig. 1 reveals two things: (1) a decrease in rate of reinforcement as compared to Hour 1 and Hour 3 and (2) an increase in rate as $\mathrm{T}_{\mathrm{E}}$ progressively increases. This double pattern is exactly what we would expect by assuming both phenomena are thermoregulatory. Second, there is close agreement between the rates of response at $37 \mathrm{deg} C$ and $45 \operatorname{deg} C$ reported here using a 14-deg reinforcement and Epstein's (1968) results at $36 \mathrm{deg} C$ and $42 \mathrm{deg} C$ using a fine spray of water. This similarity suggests that just as instrumental fur-wetting, which is an extension of salivary fur-wetting, is clearly a thermoregulatory response, so here too we are dealing primarily with a thermoregulatory and not an avoidance response.

We should also briefly note the consistent drop in efficiency from the $80 \%$ criterion level down to $50-60 \%$ as $\mathrm{T}_{\mathrm{E}}$ is elevated. This is seemingly not a mere fatigue artifact since Ss run in Condition 5 never fall below $70 \%$ in the third hour. Moreover, no $S$ ever achieved much above $90 \%$ efficiency during either training or testing. The explanation might involve the recent observation by Barofsky (1969) that high ambient temperatures produce deficits in timing behavior when Ss are tested in a differentialreinforcement-of-low-rate (DRL) schedule of reinforcement at $35 \mathrm{deg}$ C. Similarly, in this experiment, where Ss are expected to gauge the duration of the reinforcement, this deficit in timing behavior is manifest in the ability to judge the duration of the cooling burst of air. Hence, there are more responses made than there are reinforce- ments obtained. At higher temperatures, the deficit is presumably more severe.

Finally, we should attempt some account of the anomalous behavior of our Ss at $T_{E}$ of $55 \mathrm{deg} \mathrm{C}$.

In the course of developing an effective training procedure two $S s$ were trained to bar-press-for-cooling at a $T_{E}$ greater than $45 \mathrm{deg} C$. Since we considered their behavior to be principally thermoregulatory we did not expect any particular change in latency when the $S s$ were run at $T_{E}=40 \operatorname{deg} C$, but merely a reduction in reinforcement rate. We found, however, that the Ss remained prostrate in front of the bar for an hour or more and then suddenly began to respond at rates characteristic of the higher temperature range in which they were trained. This suggested that these Ss, when trained to perform at these very high ambient temperatures [where untrained rats suffer heat death in 156 min at $45 \mathrm{deg} C$ and in only $21.8 \mathrm{~min}$ at $60 \mathrm{deg} \mathrm{C}$ (Robinson, 1968)], were reacting to a generalized stress situation. In contrast, the data in Fig. 1 clearly indicates that Ss trained at $37 \mathrm{deg} \mathrm{C}$ generalize readily and in an expected manner to $T_{E}=45 \mathrm{deg} C$. If we compare the Ss trained at $T_{E}$ greater than $45 \mathrm{deg} C$ with Ss in the present study it appears that there are two distinct phenomena in operation. Namely, there is "thermal stress" when $T_{E}$ is greater than $45 \operatorname{deg} \mathrm{C}$, e.g., $55 \mathrm{deg} \mathrm{C}$, and "thermal challenge" when $T_{E}$ is at or below $45 \mathrm{deg} C$. Thermal challenge appears capable of evoking the type of precise behavior patterns that we refer to as "thermoregulatory behavior" whereas the reaction to thermal stress appears to operate as a rather crude avoidance phenomenon.

\section{REFERENCES}

BAROFSKY, I. The effect of high ambient temperature on timing behavior in rats. Joumal of the Experimental Analy sis of Behavior, 1969 12, 59-72.

CARLISLE, H. J. Heat intake and hypothalamic temperature during behavioral temperature regulation. Joumal of Comparative \& Physiological Psychology, 1966, 61, 388-397.

CARLTON, P. L., \& MARKS, R. A. Cold exposure and heat reinforced operant behavior. Science, $1958,128,1344$.

EPSTEIN, A. N., \& MILESTONE, R. Showering as a coolant for rats exposed to heat. Science, $1968,160,895-896$.

ROBINSON, S. M., BLATT, W. F., \& TEPLITZ, C. Heat tolerance of the resting and exercising rat. Canadian Journal of Physiological Pharmacology, 1968, 46, 189-194.

WEISS, B., \& LATIES, V. G. Magnitude of reinforcement as a variable in thermoregulatory behavior. Journal of Comparative \& Physiological Psychology, 1960, 53, 603-608.

\section{NOTES}

1. This research was supported by Muehlstein Fellowship Fund Grant No. 8-1010-576.

2. D. A. Kristt and J. A. Sechzer, unpublished manuscript. 